\title{
Effects of locus of a brief stimulus in a second-order schedule with pigeons
}

\author{
JENNIFER J. RICHARDS and DEREK E. BLACKMAN \\ University College, Cardiff CFI IXL, Wales
}

\begin{abstract}
On the completion by pigeons of four equal fixed intervals on one key, a light on a second key signaled that one peck on that key would be followed by food. In condition A, a brief stimulus of a further color was produced on the first key by the pecks that ended the first three (but not the fourth) fixed intervals. In condition B, no brief stimuli occurred at the end of the first three fixed intervals (tandem schedule). In condition $\mathrm{C}$, the unpaired brief stimulus was presented on the second key after the pecks on the first key that ended the first three fixed intervals. An ABACA reversal design was used. Postreinforcement pauses were longer in condition B (tandem) than in condition A, an effect similar to that reported in similar conventional one-key second-order schedules. Postreinforcement pauses in condition $\mathrm{C}$, with the brief stimulus on the second key, were also longer than in condition $\mathrm{A}$, with the brief stimulus on the first key, although similar pauses were observed after the brief stimuli in both conditions. The locus of the brief stimulus appears to affect the control it exerts over behavior in a second-order schedule.
\end{abstract}

A second-order schedule is "one in which the behavior specified by a schedule contingency is treated as a unitary response that is itself reinforced according to some schedule of primary reinforcement." (Kelleher, 1966a, p. 181). For example, a fixedinterval contingency (component schedule) may be reinforced according to a fixed ratio (overall) schedule; only the completion of a specified number of components results in primary reinforcement. Such schedules may be denoted FR x (FI y) (Kelleher, 1966a). When a brief stimulus (Snp) accompanies the end of each component other than the final component, for example, FR x (FI y: Snp), characteristic patterns of behavior may emerge which are typical of those produced by components that end with primary food reinforcement (e.g., Stubbs, 1971). Such effects have been interpreted by some (e.g., Kelleher, 1966b) in terms of conditioned reinforcement.

In nearly all studies that have investigated effects of brief stimuli in second-order schedules, the stimuli have been presented on the same response key as the schedule stimulus; that is, only one key is normally used throughout the experiment. Most experimenters who have used this procedure (e.g., Stubbs, 1971; Stubbs \& Cohen, 1972) have found shorter postreinforcement pauses in the schedule with the brief stimulus than in a similar schedule with no brief stimulus (tandem schedule). Effects on rates of responding have been less consistent (Gollub, 1977; Stubbs, 1971). However, in studies in which brief stimuli have been presented on a second key (Rose \& Fantino, 1978; Squires, Norborg, \& Fantino, 1975), postreinforcement pauses have not been shorter than in the tandem schedule. The effects of the brief stimulus seem therefore to be partly determined by its locus. The present study attempted to assess the importance of this variable in a within-subjects design.

Rose and Fantino (1978) and Squires et al. (1975) reported the effects of two-key procedures similar to conventional second-order schedules of the form FR x (FI y) with brief stimuli either at the end of every component except the last (Snp) or at the end of all components (Sp). The completion of each fixed-interval component on one key led to a light's being presented on a second key. This stimulus occurred only for a brief period, and no pecks on the second key were required except when that key was illuminated at the end of the final fixed-interval component, when a peck was followed by food. Since the same stimulus was presented on the second key at the end of every component, it was intermittently paired with food, so this schedule is reminiscent of a second-order schedule of the form FR x (Fl y: Sp) (Stubbs, 1971). Squires et al. (1975) reported the tendency of pigeons to peck at the illuminated second key at the end of successive fixedinterval components. This was taken as a measure of the pigeons' failure to discriminate their position in the sequence of stimulus presentations between successive food deliveries.

Rose and Fantino (1978) compared this two-key procedure FR 4 (FI $60 \mathrm{sec}$ ) with a tandem schedule FR 4 (FI $60 \mathrm{sec}$ ) and with an unpaired brief stimulus schedule FR 4 (FI 60 sec: Snp). With all three schedules, a stimulus appeared on the second key at the completion of the final FI 60-sec component and a response was then required on this key for food. With the tandem schedule, the second key was not illuminated at the end of unreinforced 
fixed-interval components. In the unpaired condition, the second key was briefly illuminated at the end of unreinforced components, but in a color different from that with which the key was illuminated at the end of the final component. Again, subjects pecked the paired brief stimulus on the second key and postreinforcement pauses were shorter in this schedule than in the tandem schedule. However, the subjects did not peck the unpaired brief stimulus on the second key, and there appears, from Rose and Fantino's (1978) report, to be some evidence that postreinforcement pauses were longer in the unpaired stimulus condition than in either the tandem or the paired stimulus condition (see their Figure 4, p. 339, and Figure 5, p. 400). This possibility is difficult to evaluate because Rose and Fantino compared between schedules presented within experimental sessions, and postreinforcement pauses differed in one condition as a function of the schedule with which it was being compared (see their Figure 2, p. 397, and Figure 4, p. 399).

The present experiment was designed to investigate further the effects of unpaired brief stimuli in a second-order schedule. A two-key procedure was employed similar to that reported by Rose and Fantino (1978) and Squires et al. (1975), in that the completion by a peck on one key of a final fixedinterval component led to the illumination of a key on which a peck was then followed by food. A reversal design was used, in one condition of which the completion of unreinforced components by a peck on the first key was marked by the brief illumination (in a different color) of that key, as in conventional second-order schedules with unpaired stimuli. The effects of this procedure were compared with a condition (tandem) in which no brief stimuli were presented at the end of unreinforced components and with a condition in which the brief stimulus was presented at the end of unreinforced components but on the second key, as in the Rose and Fantino study.

\section{METHOD}

\begin{abstract}
Subjects
Three adult male homing pigeons were maintained at $80 \%$ of their free-feeding weights, with water and grit constantly available in their home cages. All birds had previously been trained to eat from a food magazine, but were otherwise experimentally naive.
\end{abstract}

\footnotetext{
Apparatus

A standard two-key Lehigh Valley pigeon test chamber was used, with interior working dimensions of $34 \times 34 \times 34 \mathrm{~cm}$. To operate either key, a minimum force of $.1 \mathrm{~N}$ was required. The noise level in the chamber was $64 \mathrm{~dB}$. The chamber illumination was provided by a houselight $(2.8 \mathrm{~W}, 24 \mathrm{~V} \mathrm{dc})$. Eight seconds' access to mixed grain was used as the reinforcer. Electromechanical apparatus was used in conjunction with a Commodore PET microprocessor for programming the experiment and recording data.
}

\section{Procedure}

Each session began with the presentation of the houselight, schedule key light, and masking noise. The removal of these three stimuli marked the end of each session. The subjects were at least $21 \mathrm{~h}$ food deprived at the beginning of each session. Each session ended after the 25 th reinforcer or after $50 \mathrm{~min}$, whichever occurred sooner.

The subjects were shaped to peck the key to the right of the food hopper, and they were then exposed to a continuous reinforcement schedule for two sessions. This key was illuminated with a red stimulus except during food delivery.

The third training session started with the illumination of the left key with a white stimulus which was present throughout the session, including food deliveries. The first response on this white key produced the red stimulus on the right key. The pigeons had been trained to peck the right key for food in earlier sessions, and throughout the training and subsequent experiment it remained the only key on which a response might produce food. Although the left key remained illuminated during food presentation, the right key did not in this and all subsequent sessions in all phases. In this session, each subject pecked the right stimulus very soon after it was illuminated with red, and then food was delivered. Following food, white was the only key stimulus, and this left key served henceforth as the "schedule key," responding on which was counted as a measure of schedule and stimulus control in this and all subsequent sessions. In this session, each response on the white key produced a red stimulus on the right key and a response on the right key produced food. The schedule on the left key was changed to FI $10 \mathrm{sec}$, FI $20 \mathrm{sec}$, and FI $30 \mathrm{sec}$, with seven sessions being presented on each of these schedules. In all these and subsequent sessions, the right key was illuminated with red after the completion of schedule contingencies and a response on this key produced food.

The subjects were next required to complete two FI $30-\mathrm{sec}$ components for seven sessions and then three Fl 30-sec components for seven sessions. After the completion of each component except the final one, a green brief stimulus appeared on the schedule key (green replacing the white stimulus for $2 \mathrm{sec}$ ).

Following this training, the subjects were placed in the first phase (A) of the experiment, FR 4 (FI $30 \mathrm{sec:} \mathrm{Snp).} \mathrm{Contingencies}$ were similar to those in the final training schedule, except there were now four FI 30-sec components between food presentations.

Figure 1 shows, in diagrammatic form, the colors of the two keys throughout the various phases of the experiment.

After 20 sessions in this condition, the pigeons were exposed to the tandem FR 4 (FI $30 \mathrm{sec}$ ), in which the contingencies were

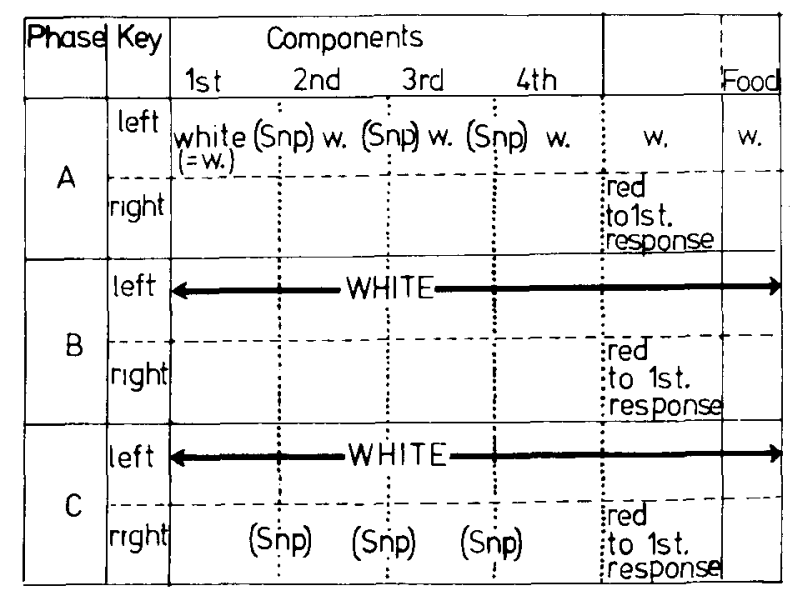

Figure 1. Colors of the two keys throughout the various phase of the experiment. Phase A, FR 4 (FI 30 sec: Snp), the one-key procedure; Phase B, tandem FR 4 (FI 30 sec: Snp); Phase C, FR 4 (FI 30 sec: Snp), the two-key procedure. 
similar to those in phase A except that no green brief stimuli were presented. The birds were in this phase for 15 sessions and were then again exposed to phase $A$ for 15 sessions.

Phase $\mathrm{C}$ then began. Contingencies were similar to the procedure in phase A with the FR 4 (FI 30 sec: Snp) schedule, except that the green 2 -sec brief stimuli now occurred on the right key at the completion of the first three components. When these brief stimuli were presented, the left key remained illuminated with the white schedule stimulus. Following 20 sessions in this condition, the subjects were again exposed to phase $\mathbf{A}$ for a final 10 sessions.

\section{RESULTS}

Figure 2 shows the mean daily postreinforcement pause in seconds for each subject. In phase B (the tandem condition), pauses were longer than in phase $\mathbf{A}$ (with the brief stimulus on the left key) with all subjects. In phase $C$ (stimulus on the right key), postreinforcement pauses again increased to values similar to those maintained in the tandem schedule (B) with P1 and P2. Pauses were occasionally very long with $\mathrm{P} 3$, and where data points are missing this is an indication that only one food delivery or less occurred in the session.

With a traditional operant reversal design, attention is nearly always attached to the stable behavior maintained by contingencies after prolonged exposure to a schedule rather than to transitional behavior that occurs when a schedule is first introduced at the beginning of a phase (Sidman, 1960). Figure 2 shows an abrupt increase in postreinforcement pause duration with the transition from phase $A$ (with the brief stimulus on the left key) to phase B (the tandem schedule), but a much

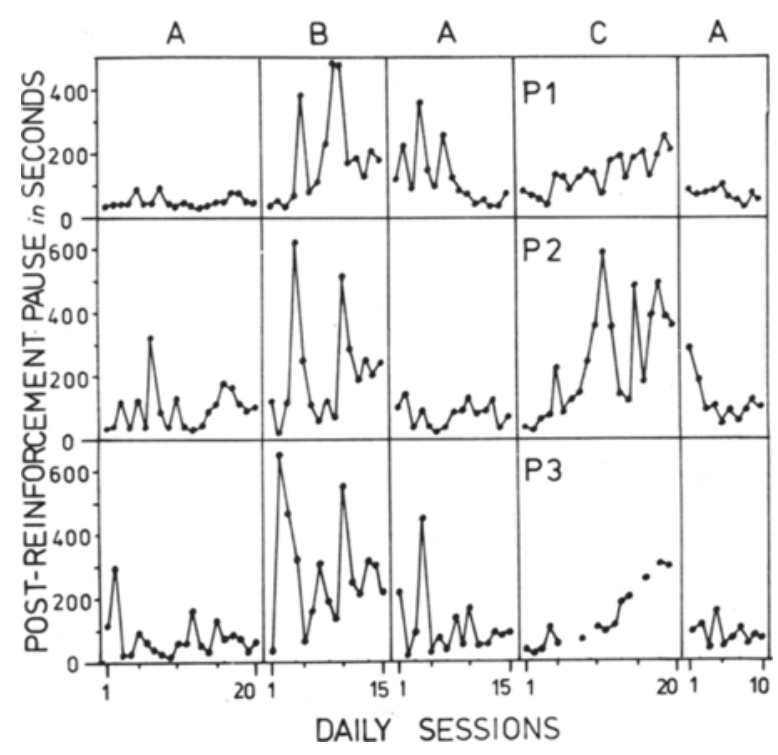

Figure 2. Daily mean postreinforcement pauses in seconds for each subject. Phase A, FR 4 (FI 30 sec: Snp), the one-key procedure; Phase B, tandem FR 4 (FI 30 sec: Snp); Phase C, FR 4 (FI 30 sec: Snp), the two-key procedure.

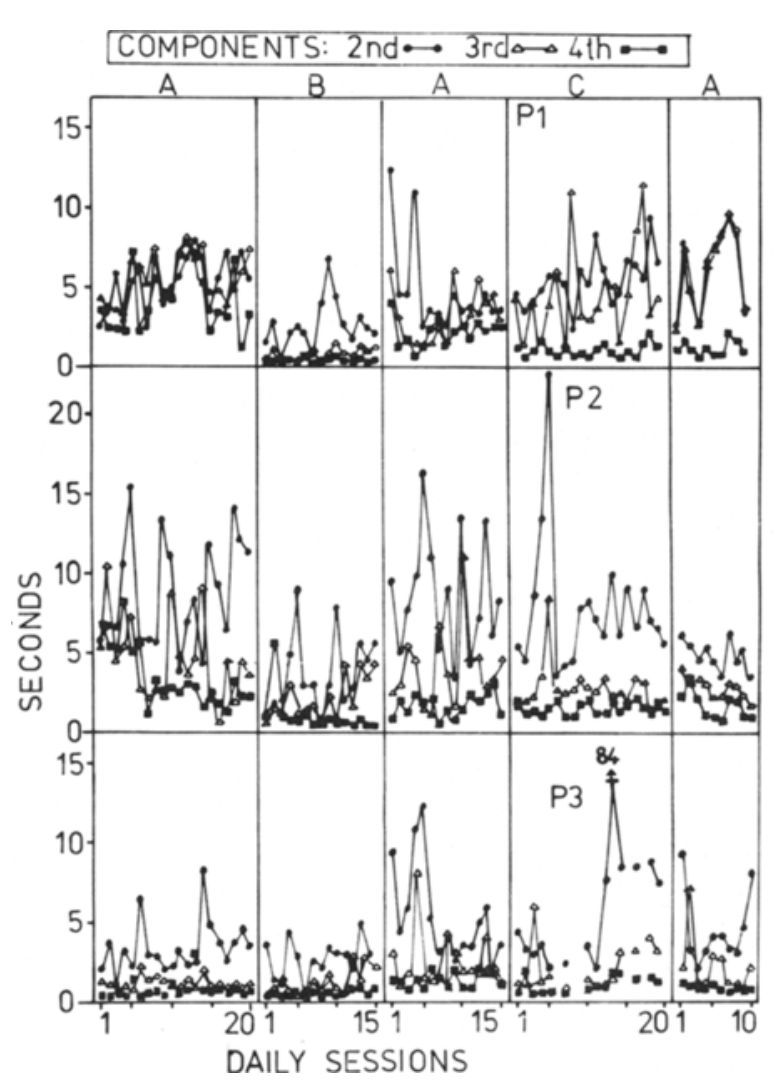

Figure 3. Daily mean pauses at the beginning of the second, third, and fourth components in seconds for each subject. Phase A, FR 4 (FI 30 sec: Snp), the one-key procedure; Phase B, tandem FR 4 (FI 30 sec: Snp); Phase C, FR 4 (FI 30 sec: Snp), the two-key procedure.

more gradual increase from the third phase (A) to phase $C$ (with the brief stimulus on the right key). These transitions, however, both ultimately resulted in an increase in postreinforcement pause duration by the sixth session in both phase $B$ and phase $C$ with all subjects. It is this behavior, maintained by the schedule after prolonged exposure to contingencies, which forms the focus of interest in the operant design used here and which forms the basis of the discussion of the data in Figure 2 and of the data considered below.

Figure 3 shows the daily mean pause at the beginning of the second, third, and fourth components in seconds for each subject. This was calculated from the beginning of each of these components (at the end of the brief stimulus in phases $A$ and $C$, and at the final response of the preceding component in the tandem schedule, B) to the first response in that component. The figure shows that when a brief stimulus occurred (in either conditions $\mathrm{A}$ or $\mathrm{C}$ ) it was followed by a longer pause than when there were no brief stimuli to mark the end of components, the tandem schedule $B$.

Rates of responding were also computed for each 
component for each animal. These were calculated as responses per second, from the first response to the last in each component. These data are not presented, however, because they remained consistent throughout all conditions with all subjects, hence showing no differential effects in the different types of schedules used. Response rates increased through the first to last component in the schedule with all subjects. In the first component, there was generally only one response, which terminated that component. Then there were approximate rates of .7 responses/ $\mathrm{sec}$ in the second component, 1.0 responses/sec in the third component, and 1.2 responses $/ \mathrm{sec}$ in the fourth component, these data being the mean for all three birds.

The number of pecks at the brief stimulus, when it was presented on either key, were monitored. In both brief stimulus conditions, there were almost no pecks on the key on which the brief stimulus was presented. When the brief stimulus was presented on the separate right key rather than on the schedule key, the subjects also stopped responding on the left schedule key for this 2 -sec period. Only a few responses were recorded on the left key during these 2 -sec periods over each session in this phase.

\section{DISCUSSION}

The results suggest that the nature of the control acquired by the brief stimuli was influenced by their locus.

Subjects were trained with the one-key brief stimulus schedule (A), rather than the tandem schedule, because results in the literature (e.g., Kelleher, 1966b) had suggested that stable behavioral control might be facilitated using this procedure. The behavior shown in phase A seems typical of that reported in the literature on effects of brief stimuli in second-order schedules (e.g., Kelleher, 1966a; Stubbs, 1971; Stubbs \& Cohen, 1972). Postreinforcement pauses were shorter than in the tandem schedule (B), and there was a pause after each brief stimulus (the pauses after earlier brief stimuli being longer). No effects were shown on response rates, but few consistent effects on rate have been reported (Stubbs, 1971).

In phase $\mathrm{C}$, when the brief stimulus was presented on a second key, postreinforcement pauses increased. In every respect, except for this feature, the procedure used was identical to that in phase A. Yet the behavior maintained in these phases was different. It is difficult to understand why the location of the brief stimulus should have this effect on postreinforcement pause duration, given that it appeared on an identical schedule in all experimental phases and was always presented within the subject's range of vision no matter on which key it occurred. Perhaps it was possible that the subjects did not "attend to" or "notice" the brief stimulus when it occurred on a separate key from the schedule light. Yet, results showed that in phase $C$ the subjects did pause after the stimuli were presented, as they did when the stimulus was on the schedule key in phase $A$. It is therefore worth noting that, in this respect, the brief stimuli acquired a similar function in both brief stimulus procedures.

The present results suggest, then, that the duration of the postreinforcement pause was determined, at least in part, by the key on which the brief stimulus was presented. Very little work has been conducted with a two-key procedure in second-order schedules, the only published research being that reported by Rose and Fantino (1978) and Squires et al. (1975). The results of the Squires et al. study are difficult to interpret in the present context, however, because, as noted earlier, no tandem control condition was used. The results of the Rose and Fantino study are also difficult to interpret because of the multiple design in which one experimental schedule alternated with a second schedule within each session and interactions were seen to have occurred. However, allowing for difficulties of interpretation, Rose and Fantino's results, with a two-key procedure, are different from results with a traditional one-key procedure. With the latter procedure, postreinforcement pauses in second-order schedules with brief stimuli are shorter than in comparable tandem schedules. This is not the case with a two-key procedure. The present experiment investigated the effects of locus of a brief stimulus by comparing a one-key with a two-key procedure within the one experiment. Previous results were replicated: behavior maintained with the two-key procedure was different from that maintained by the one-key procedure.

The results of the present experiment show a conventional facilitatory effect of a brief stimulus presented on a schedule key in a second-order schedule, in that postreinforcement pauses were relatively short. However, no such behavioral effect was exerted when the stimulus was presented according to an identical schedule but on a second key, although all food presentations were obtained by pecks on that second key. It seems, from the data presented, that the stimuli on the second key were seen by the pigeons. The reasons for the behavioral differences attributable to the locus of the brief stimuli are not clear, and no current theoretical interpretation of second-order control seems to handle the findings (Mackintosh, 1974; Stubbs, 1971).

\section{REFERENCES}

Gol,.ur, L. R. Conditioned reinforcement: Schedule effects, In W. K. Honig \& J. E. R. Staddon (Eds.), Hondbook of operant hehavior. Englewood Cliffs, N.J: Prentice-Hall, 1977.

Krtlturk, R. T. Chaining and conditioned reinforcement. In W. k. Honig (Ed.), Operant behavior: Areas of research and 
applicarion. New York: Appleton-Century-Crofts, 1966. (a) Kilt.tiF R. R. T. Conditioned reinforcement in second-order schedules. Journal of the Experimental Analysis of Behavior, $1966.9 .475-485$. (b)

MAckivrosil. N. J. The psychology of animal learning. London: Academic Press, 1974.

Rosf. J. F.., \& Fantino, E. Conditioned reinforcement and discrimination in second-order schedules. Journal of the Experimental Analysis of Behavior, 1978, 29, 393-418.

Sinman, M. Tactics of scientific research. New York: Basic Bonks, 1960.

Squirf's, N. K., Norbora, J., \& Fantino, E. Second-order schedules: Discrimination of components. Journal of the Experimental Analysis of Behavior, 1975, 24, 157-171.

Stubis, D. A. Second-order schedules and the problem of conditioned reinforcement. Journal of the Experimental Analysis of Behavior, 1971, 16, 289-313.

StubBs, D. A., \& Cohen, S. L. Second-order schedules: Comparison of different procedures for scheduling paired and nonpaired brief stimuli. Journal of the Experimental Analysis of Behavior, 1972, 18, 403-413.

(Received for publication January 29, 1980; revision accepted April 23, 1980.) 